\title{
La prensa anarcofeminista: una "incisiva" plataforma escritural en el periódico La Voz de la Mujer
}

\author{
Anarcha-Feminist press: an "incisive" writing plataform in the \\ newspaper La Voz de la Mujer \\ Leticia Contreras Candia \\ Pontificia Universidad Católica de Chile \\ Itcontreras@uc.cl
}

\begin{abstract}
Resumen: Este artículo analiza los espacios de (auto)representación disidentes a los imaginarios hegemónicos de modernización nacional configurados en el periódico comunista-anárquico argentino La Voz de la Mujer (1896), en concreto analizaremos una columna, sin título, firmada por Pepita Guerra. Con este propósito, adoptaremos un enfoque crítico desde los estudios de género que permita explorar las luchas ideológicas del sistema sexo-género en la Argentina decimonónica. Encontramos en el ejercicio escritural de Pepita Guerra la articulación de subjetividades alternativas, en clave feminista, que fisuran los ordenamientos corporales y los imperativos de género femenino elaborados por el discurso estatal del siglo XIX.
\end{abstract}

Palabras clave: anarcofeminismo, prensa de mujeres siglo XIX, contracultura decimonónica.

\begin{abstract}
This article analyzes the dissident (self) representation spaces to the hegemonic imaginary of national modernization configured in the Argentine communist-anarchic newspaper La Voz de la Mujer (1896), specifically we will analyze a column, without title, signed by Pepita Guerra. With this purpose, we will adopt a critical approach from gender studies that allows us to explore the ideological struggles of the sex-gender system in nineteenth-century Argentina. We find in Pepita Guerra's scriptural exercise the articulation of alternative subjectivities, in a feminist key, that fissure the body orders and the feminine gender imperatives elaborated by the 19th century state discourse.
\end{abstract}

Keywords: anarcofeminism, nineteenth-century women's press, nineteenth-century counterculture.

Recibido: 05/03/2019

Aceptado: 01/06/2020 
La prensa del siglo XIX, a través de la redacción de periódicos, diarios, revistas entre otros formatos, se transformó en un importante soporte comunicacional para llevar a cabo la tarea de advertir a los lectores sobre las ideas hegemónicas emanadas del Estado y su burguesía letrada. Según el crítico Julio Ramos, la prensa al instalar el debate sobre nociones como: civilización/barbarie, consolidación y modernización del aparato estatal o el de cultura nacional, desencadenó la generación de un centro donde proliferaron nuevos sujetos nacionales. El periodismo comienza a mediatizar el influjo del Estado inaugurando así múltiples campos de acción; autonomizándose del rigor de la elocuencia para dar cabida a lenguajes-otros, códigos-otros, símbolos nacionales resquebrajados e identidades múltiples.

Las mujeres ingresaron a este espacio discursivo, otorgando a sus reflexiones sobre el discurso dominante una clara proyección pública. Desde la escritura y la posterior publicación de sus textos/discursos, las mujeres, ahora escritoras, articularon una voz propia que resignificó las categorías asignadas por la cultura oficial. Los tópicos abordados por la prensa femenina, iban desde el rol de la maternidad en la construcción de una sociedad civilizada hasta las relaciones exteriores, el espectro de temáticas es amplio pues sus inquietudes responden a las coyunturas políticas que hipercodificaron sus contextos de producción. Por este motivo, se explica que las primeras publicaciones escritas por y para mujeres se gestaran en los círculos privilegiados de la sociedad, ya que las tasas de alfabetización eran muy bajas en las primeras décadas del siglo XIX y más aún para las mujeres, pero esto no significó que la cultura de mujeres se depositara exclusivamente en las clases favorecidas (Masiello 118).

En sectores de obreros asalariados e inmigrantes y en repudio al modelo social imperante, emerge con fuerza la prensa anarquista. En la ciudad de Buenos Aires, a través del financiamiento autogestionado y donaciones de militantes, circuló un número importante de ejemplares anarquistas, entre los cuales destacaron " $E l$ Rebelde, 1898-1903; El Perseguido, 1890-1897; Germinal, 1897-1898; L'Avvenire, 18961904; La Batalla, 1910; La Montaña, 1898; La Vanguardia, 1894-1910; La Voz de la Mujer, 1896-1897; Luz al Soldado, 1908-1913" (Padilla 11).

Serán los periódicos Germinal, El Oprimido y esencialmente La Voz de la Mujer, en la figura de sus escritoras, que se hicieron cargo de discutir las ideas sobre la emancipación de la mujer. La imbricación de las propuestas feministas con la corriente ideológica anarquista, desbordarán de sentidos la retórica femenina de periódicos como La Alborada o El Búcaro Americano, publicaciones vinculadas a mujeres escritoras provenientes de sectores acomodados, pues resultaba "evidente que la mujer no era, no es, una clase, no estaba uniformemente oprimida, ya que el sexismo no afectaba a todas de igual manera. Las privilegiadas tenían poco en común con la mujer obrera" (Fernández-Martorell 63). 
La Voz de la Mujer era un periódico pequeño, semiclandestino y de tendencia comunista-anarquista dirigido a la clase trabajadora. Sin embargo, reivindicaba los derechos de las mujeres, vinculándose de esta forma a las luchas entabladas por el movimiento feminista. En efecto, fue entre las mujeres trabajadoras de los centros urbanos que La Voz de la Mujer emplazó sus discursos libertarios, por lo tanto, promovía la descomposición y recomposición de los roles tradicionales asignados a las mujeres, reconociendo la especificidad de su opresión e invitándolas a movilizarse contra la subordinación impuesta por el sistema patriarcal y capitalista. Este periódico publicó, entre 1896-1897, solamente nueve números y al igual que otras expresiones de la prensa anarquista aparecía esporádicamente. De los números uno al cuatro se publicaron mil ejemplares, los números cinco, siete y ocho alcanzaron un tiraje de dos mil ejemplares; finalmente, el último número publicó mil quinientas copias, cifras considerablemente importantes para un periódico de las características de $L a$ Voz de la Mujer. Al principio publicaban una vez cada tres semanas, luego el tiempo de espera entre número y número se extendió de seis semanas a dos meses, esta inestabilidad en la emisión del periódico se debía, por un lado, a la falta de financiamiento y, por otro, a la persecución policial (Masiello 138).

Las ediciones periodísticas anarcofeministas decimonónicas se resisten a la normalización y normativización de la lengua, objeto de disciplinamiento y exclusión, pues avizoran en la multiplicidad de registros lingüísticos la posibilidad de atender a otras perspectivas, asumiendo la integración efectiva de todos los sujetos que componen el entramado social-cultural. A partir de una aguda crítica a los procedimientos discursivos estatales, las escritoras anarcofeministas producirán importantes re-significaciones respecto a los ordenamientos simbólicos de género, al erotismo y la sexualidad femenina, además de permeabilizar las propuestas sobre la maternidad. Instancia socio-cultural unívoca para las mujeres, la cual se configuró como un complejo de consolidación nacional, tanto para la oficialidad como para mujeres escritoras de sectores acomodados. Las publicaciones anarcofeministas, detectan en la familia, el espacio por excelencia de la doble opresión ejercida sobre las mujeres: son esclavas de la burguesía capitalista en el trabajo (por ejemplo, en las fábricas) y esto no termina con su regreso al hogar, pues allí son víctimas de la esclavitud impuesta por sus esposos, obreros al igual que ellas.

Las repercusiones por entablar el debate sobre el rol de la mujer, pero desde un enfoque que perseguía transformaciones radicales en los modelamientos sociales, no se hicieron esperar. Las colaboradoras de diarios anarquistas fueron duramente perseguidas y violentadas, generalmente calificándolas de mujeres de vida licenciosa o lisa y llanamente de prostitutas. Intelectuales de la talla de Juan Bautista Alberdi creían sobre las mujeres pioneras exploradoras del espacio público que: 
Mientras la mujer viva en la calle y en medio de las provocaciones, recogiendo aplausos, como actriz, en el salón, rozándose como un diputado entre esa especie de público que se llama la sociedad, educará los hijos a su imagen, servirá a la República como Lola Montes, y será útil para sí misma y para su marido como una Mesalina más o menos decente (44).

Habitar en el mundo exterior, expone a las mujeres al contacto con otros cuerpos, a las fluctuaciones de la "calle", el intercambio de experiencias fuera del hogar la tornarán un ser inmoral; vicioso. El único lugar posible para la mujer que accede e interviene en la esfera pública es el de la transacción sexual de su cuerpo, convirtiéndose en una cortesana como Lola Montes o en la patricia Mesalina. La producción periodística femenina del siglo XIX en Latinoamérica, constituyó una importante plataforma escritural que permitió a las mujeres instalarse en el debate público respecto a temáticas, tales como: la política, la cultura y la emancipación femenina. Las escritoras deben movilizarse en un convulsionado contexto, donde las emergentes repúblicas americanas concentran todos sus esfuerzos, en unificar sus territorios y homogeneizar la población, con el objetivo de consolidar Estados-naciones modernos.

Frente a los ejercicios de poder articulados por la élite argentina, las mujeres, a través de la escritura, interpelaron los ordenamientos discursivos impuestos por los grupos de poder creando intersticios, tensiones y márgenes subversivos, en clara oposición a los mecanismos de sujeción ejercidos sobre los sujetos marginales. En esa dirección, una de las voces insubordinadas al régimen hegemónico de la élite surgió de las filas anarquistas, específicamente del periódico La Voz de la Mujer. En él sus redactoras elaboraron agudas críticas a la dominación masculina, eclesiástica y estatal padecida por las mujeres. Ellas, mediante sus artículos expresan la realidad social de las mujeres, pero también la cambian, contradicen y niegan; intentan revelar un entramado simbólico disidente al imaginario androcéntrico. Ante el amplio espectro de diarios, periódicos y revistas femeninas, publicadas en la Argentina decimonónica, nos encontramos con una propuesta escritural que desafiaba los discursos e imaginarios modernizadores de la nación.

\section{E1 "amor libre" de Pepita Guerra}

Pepita Guerra, una de las principales colaboradoras del periódico La Voz de la Mujer, publica un artículo en contra del Estado, la Iglesia Católica y la burguesía el 20 de febrero de 1896. Desconocemos datos biográficos que revelen, por ejemplo, su verdadero nombre, ocupación o vínculos familiares. No obstante, la figura de Pepita Guerra alcanzó gran notoriedad al interior de los círculos anarquistas de finales del siglo XIX, principalmente por sus mordaces textos doctrinarios que denunciaban la doble sujeción de las mujeres en la sociedad argentina de fin de siglo. En 
ese sentido, el tema de la emancipación de la mujer, ocupa un lugar prioritario en su producción escritural. Particularmente, en el texto intitulado de Pepita Guerra observamos la instalación de un discurso propio sobre el erotismo y la sexualidad femenina, atravesado por el deseo y la voluntad de la escritora que interfiere las representaciones estatales de la estirpe nacional.

Siguiendo la noción de interferencia crítica elaborada por Edward Said, nos interesa "abrir la cultura a experiencias del Otro que han quedado 'fuera' (y que han sido reprimidas o enmarcadas en un contexto de hostilidad polémica) de las normas elaboradas por los "entendidos" (161), ya que durante bastante tiempo las voces académicas autorizadas —al no estudiar este tipo de producciones escrituralesno contemplaron el ingreso al sistema literario canónico de los textos producidos en el margen. Lo anterior, debido al carácter subversivo de estos textos, su incompatibilidad con las preceptivas de estilo imperante o, en muchos casos, su desplazamiento por resistirse a la normativa de los géneros literarios y sexuales, entre otras consideraciones. Teniendo en cuenta que, el gran referente literario decimonónico legitimado tradicionalmente en los planes y programas educacionales, para la comprensión de los proyectos nacionales, fue la novela, ya que ahí se encontraban las pautas de comportamiento social basadas en los procesos civilizatorios y las metáforas de identidad unificada. Por esta razón, cualquier texto híbrido fue clausurado, invisibilizando las voces heterogéneas; un ejemplo de esas voces silenciadas fueron los artículos publicados en La Voz de la Mujer.

Al iniciar un recorrido analítico por el texto de Pepita Guerra, resulta revelador observar la ausencia de un título o encabezado que preceda el cuerpo del artículo. En Ante la Ley, Derrida reflexiona respecto a las características y disposición del título en una obra, indica que su localización se encuentra determinada por la prescripción de leyes convencionales, fijándolo espacialmente: antes y arriba, del cuerpo del texto. De este modo, la elección del título recaería en la figura del autor o por los representantes editoriales, adjudicándose estos la propiedad del título. Frente a este contexto, el título establecería la operación de nombrar y garantizar la identidad, la unidad y los límites de la obra original que titula (5). El hecho de prescindir de un título, reviste de un halo fantasmagórico al locus que potencialmente debía ser ocupado por aquella estructura. Así pues, esa zona "vacía" satura de perplejidad al lector(a), ahora se ve a sí mismo(a) desprovisto(a) de esa mano reguladora que orientaba sus pasos, invitándolo(a) a internarse en el cuerpo del texto. Las certezas proporcionadas por la ley del título, son puestas en cuestionamiento, dando paso a las dudas del lector(a); permitiendo un tráfico oscilante entre él/ella y la corporalidad escritural. Al descartar el título, la sujeto de la enunciación, difumina los límites de este texto y efectúa escisiones sobre la pretendida unidad discursiva. Este procedimiento, llevado a cabo en el artículo de Pepita Guerra, 
tiene importantes alcances concernientes a la política de resistencia afirmada por el movimiento anarcofeminista y al disciplinamiento de la población propugnado por el proyecto nacional republicano.

En primer lugar, debemos recordar el activo rol desempeñado por la lengua, en los esfuerzos de uniformar lingüísticamente a los ciudadanos de los incipientes Estados-naciones americanos. Este deseo de homogenización de la lengua, se expresó en la Gramática de la lengua castellana destinada al uso de los americanos, diseñada por Andrés Bello, en la que se recogía el espíritu del "buen decir" a través de los adecuados usos, los que debían ser efectuados por los ciudadanos americanos de la lengua. Es así como, hasta los vocablos propios de cada región o grupo étnico, fueron desplazados por un ideal nacionalista.

En este marco, las normativas escriturales, elaboradas por la élite letrada, sancionaron todo aquel texto que no se ciñera a las reglas de estilo, género, o formato dispuestas por ellos. Al irrumpir en la escena, Pepita Guerra publica un texto sin título, ambiguo en el formato escogido para su publicación, que denunciaba la subordinación experimentada por las mujeres en la sociedad de 1896. Indudablemente, dicho texto desestabiliza la matriz discursiva nacional y pone en entre dicho las preceptivas escriturales de la élite letrada argentina, resistiéndose al ordenamiento social engendrado en un diseño lingüístico que excluye la heterogeneidad propia de la lengua y de la comunidad lingüística que la vitaliza.

A raíz, de la operación deconstructiva del título, en la cual se manifiesta un juego de apariencia y ocultamiento, observamos una segunda repercusión efectuada por Pepita Guerra, en el seno del proyecto discursivo nacional argentino. Con una clara intención comunicativa, el título es suprimido para intentar recuperar fragmentariamente sustratos de oralidad, dimensión intrínseca de la lengua, pero que ha sido relegada a un segundo plano debido a la preeminencia otorgada al discurso, y en este caso particular a la normalización escritural de los letrados. Se produce un desplazamiento, desde el espacio "caótico" de la oralidad hacia el "sistémico" espacio del texto escrito, ya que desea inundar al texto del flujo energético propio de las proclamas pronunciadas en el espacio público.

Por esta razón, Pepita Guerra emprende su artículo interpelando a un sector subordinado en particular, su arenga tiene como destinataria principal a las mujeres de la sociedad argentina. Ahora bien, el distanciamiento entre la sujeto de la enunciación y las aludidas, no perdura demasiado tiempo, pues, a través de una determinación lingüística, representa su identidad, se integra como una más al conglomerado de mujeres, simultáneamente perpetra una diferenciación respecto a otros sectores sociales. Teniendo clara conciencia del lugar marginal que desempeña en la sociedad, interroga a las mujeres y a sí misma sobre la categoría "mujeres" a la cual han sido circunscritas, su respuesta es escueta pero vital para el ejercicio 
de subjetivación emprendido en el texto, pues se está articulando un lenguaje que configura una re-presentación en el sentido del darstellen, vale decir, tener la capacidad de enunciar y elaborar un espacio semiótico propio (Spivak 56). Así es representado en el texto a través de un tono decidido y beligerante:

¡Jóvenes, niñas, mujeres en general, de la presente sociedad!

Si no queréis convertiros en prostitutas, en esclavas sin voluntad de pensar ni sentir; no os caséis!

Vosotras, las mujeres, ¿qué somos? ¡algo! ¿qué se nos considera? ¡nada! (Pepita Guerra 237)

En el momento de sostener la subvaloración que los otros asignan a la categoría "mujeres", acertadamente denuncia la construcción mediatizada de dicha categoría y sindica a "otros" como los responsables de la lamentable situación en que se hallan las mujeres. Sin embargo, resignifica el esencialismo del constructo "mujeres" y presume que en esa definición se encierra algo más, pero no asume la tarea de asignar una conceptualización identitaria cerrada, por el contrario, deja abierta, en una suerte de entre paréntesis las potenciales definiciones del ser "mujer" o "mujeres". Ahora bien, en el texto de Pepita Guerra existe claridad respecto a la desidia y las degradaciones experimentadas por las mujeres en la sociedad. En concreto observa en la figura de la prostituta una víctima de las desigualdades del sistema de producción, pero sobre todo que es una obediente esclava del patriarcado, por lo tanto, la imagen de la esposa funcionaría como un significante que se encuentra en el mismo orden simbólico del significante prostituta, es decir, la sujeto de la enunciación operacionaliza procesos de identificación similares para la prostituta y esposa; pues construye una representación analógica entre ambas al indicar que al momento de contraer matrimonio las mujeres-esposas se transforman en mujeres-esposas-prostitutas. Respecto al proceso de identificación Stuart Hall sostiene que: "a lo largo de sus trayectorias, las identidades pueden funcionar como puntos de identificación y adhesión sólo debido ${ }^{1}$ a su capacidad de excluir, de omitir, de dejar 'afuera', abyecto" (19). De acuerdo a lo anterior, observamos una interesante tensión al inicio del manifiesto sobre la emancipación de la mujer configurado por Pepita Guerra; por una parte, advierte que una forma de evitar el yugo masculino radicaría en no acceder a los enlaces matrimoniales y, por otra, rechaza vehementemente a aquellas mujeres-esposas por transformarse en mujeres-esposas-prostitutas, vale decir, construye políticamente un "nosotras" hostil al dejar "afuera" a cualquier mujer que no siga su imperativo programático del "amor libre”.

1 El uso de cursiva corresponde al texto original. 
Tal vez, esa política “otra” que surge del texto está dada por la definición inacabada del proceso de identificación femenino y por eso no existiría un vínculo solidario, por ejemplo, con mujeres burguesas o simplemente otras mujeres. Zygmunt Bauman indica sobre el compromiso ético con el otro que: "Seguir el impulso moral significa asumir responsabilidad por el otro, lo cual lleva a su vez a participar en su destino y a comprometerse con su bienestar" (65). Pepita Guerra confía que su compromiso debe estar solamente con las mujeres obreras, sin embargo, no visualiza que en ese gesto excluye a las demás mujeres víctimas del heterocapitalismo; incurriendo en una violencia simbólica y efectiva propio de la máquina de producción androcéntrica. En ese desplazamiento se propicia un nuevo relato de violencia y sujeción, claro que ahora, desde el interior del colectivo "mujeres" que denuncia la opresión que ahora ellas mismas ejercen sobre sus pares.

En lo que concierne a la singularización de los "otros", agresores del cuerpo femenino; el matrimonio es una de las instituciones promotoras de la subordinación femenina. Este enlace es el soporte de la familia heterosexual, puesto que los contrayentes deben ser una mujer y un hombre, es decir, debido al cumplimiento de dicho contrato civil, ${ }^{2}$ la familia argentina constituye plenamente un Aparato Ideológico de Estado (Althusser 131), pero ¿cómo se comporta este AIE en la sociedad decimonónica argentina?

Para los intereses del proyecto nacional argentino, la celebración de matrimonios fundaba el soporte de la familia nacional argentina; espacio ideológico donde recaían los valores nacionales de patriotismo, virtud, civilización y progreso. Lucía Guerra señala que la alegoría patriótica de la nación, vista como una gran familia, posee un cuerpo de mujer, delineada como la madre-nación desexualizada (113). El cuerpo femenino es instrumentalizado en función de los propósitos perseguidos por los grupos de poder, en el caso de las mujeres de la élite, su tarea reproductiva radica en el blanquemiento y mejoramiento de la población argentina, en cambio, las obreras y sus hijos levantarían la economía nacional, alcanzando la tan preciada civilización y modernización para un grupo delimitado.

En resguardo del matrimonio heterosexual, la literatura del siglo XIX suministró un amplio catálogo de novelas, ${ }^{3}$ donde el amor romántico e idealizado, ajustado

2 La primera ley de matrimonio civil, a nivel provincial (en Santa Fe), se dictó en septiembre de 1867 durante el gobierno de Nicasio Oroño. Sin embargo, debido a presiones de la Iglesia Católica y grupos conservadores, bajo el gobierno de Mariano Cabal en el año 1868, se derogó la ley de matrimonio civil. Recién veinte años después, en 1888, se modificó el código civil instaurando el matrimonio civil, sin distinción de religión (o ausencia de ella) de los cónyuges.

3 Véase el trabajo de Doris Sommer, Ficciones Fundacionales (2007). Allí revisa la relación del amor y la patria (presentes en las novelas del siglo XIX), en la configuración de alegorías nacionales latinoamericanas. 
a las normativas corporales y de clase, conducía a enlaces felices y beneficiosos para el desarrollo nacional. Resultan, desde la perspectiva de la sujeto del enunciado, una seductora trampa para las incautas mujeres, que ven en el matrimonio y la posterior constitución del "hogar", un refugio de los abusos vividos en el espacio público. Por el contrario, en aquel "hogar" padecerán otra muestra de opresión, proporcionada también por un integrante de los "otros". Así es explicado en el texto: "Vosotras las que pensais [sic] encontrar amor y ternezas en el hogar, sabed que no encontraréis otra cosa que un amo, un señor, un rey, un tirano” (237).

La escritora, entonces, es detractora del matrimonio por reproducir la corrupción e intereses nacionales, además de visualizar la jerarquía sexo-genérica que alberga la familia, la cual privilegia a los hombres. Distanciándose de otros periódicos femeninos de la época, en este texto se instala la voz de un cuerpo femenino erotizado, ávido de amar y plagado de deseo, el cual transita oscilante frente al objeto deseado. En la autorepresentación de su sexualidad, la sujeto se posiciona activa frente a otro(s) cuerpo(s) y en un movimiento cadencioso libera su voluptuosidad, estableciendo de esta forma operaciones de transformación en el deseo mismo y las potenciales direcciones que podría tomar este. En este sentido, el erotismo y sexualidad femenina, al igual que la masculina, también pueden sufrir alteraciones, no se puede disponer de ellas como identidades fijas.

En relación a lo anterior, el matrimonio ordenaría a los sujetos contrayentes bajo determinados usos y funciones corporales, por ejemplo, en el caso de las mujeres como virtuosas madres y sumisas esposas. En consecuencia, dicha institución definiría la conducta del deseo femenino, exclusivamente en función de la procreación, instrumentalizando, pero además dotando de coherencia el género femenino. Las mujeres, adscribiéndose al matrimonio, aceptan convertirse en esclavas de los requerimientos masculinos; la dominación androcéntrica extenderá su tiranía sobre el cuerpo femenino. Por este motivo, Pepita Guerra las insta a tomar conciencia de esta injusta condición, pero además las invita a revertirla proclamando su pública aversión al matrimonio.

Pepita Guerra es una opositora acérrima del matrimonio, por considerarlo una narrativa estatal impuesta a las mujeres, a través de una serie de jurisprudencias, que violan su integridad como individuo(a)/ciudadano(a). De manera puntual, se refiere a la incapacidad de denunciar los actos vejatorios y agresiones, tanto físicos como psicológicos, propinados por los maridos o simplemente se les niega la posibilidad de decidir dar fin al enlace. ${ }^{4}$ Resulta imposible para las mujeres casadas

4 En la novela autobiográfica Peregrinaciones de una paria (1839), de la escritora Flora Tristán, narra las exclusiones padecidas, durante su estadía en Perú, debido a su doble condición de hija natural y esposa separada. Su esposo, André Chazal, le inflige golpizas que terminan por hacer huir del "hogar" a Flora, 
efectuar estas políticas de inversión de los saberes-poderes instituidos en el matrimonio, pues perturbarían la congruencia, unidad y legitimidad estatal. Al respecto, Pepita Guerra afirma:

Miles de casos se ven en que una infeliz mujer huye del hogar marital, no quiero saber por qué causa, sea ella cualquiera, el caso es, que el marido acude á [sic] la autoridad y ésta obliga á [sic] la esposa á [sic] ir nuevamente al lado del hombre á [sic] quien detesta y odia.

¡Más no hiciera un pastor con una oveja ó [sic] cabra! (237)

En el fragmento anterior, observamos el intersticio provocado en el locus por excelencia de la familia nacional: "el hogar". La ficción del hogar como un espacio idílico pierde terreno en el imaginario femenino, específicamente en el colectivo de mujeres obreras, víctimas de la doble explotación capitalista/patriarcal, ahora ellas a raíz de la industrialización de la sociedad argentina transitan entre el espacio privado y el público, confirmando los abusos perpetrados en ambas dimensiones. No obstante, para detener el flujo de insurrecciones femeninas al interior del matrimonio, los maridos cuentan con el aparato represivo del Estado (el cuerpo policial y la narrativa legal), que restablecerá el orden, devolviéndoles a la fugitiva; objeto de su propiedad. El cuerpo femenino ingresa al sistema de intercambio económico, pero en el terreno de lo devaluado y silenciado de sus voces.

Ahora bien, en el texto se produce una fuga de sentido en relación a la opción castradora del matrimonio. Si bien, Pepita Guerra ataca al matrimonio no se opone a las uniones entre mujeres y hombres, ni menos a la maternidad. ${ }^{5}$ La siguiente expresión lo corrobora: "y crie dos, cuatro ó [sic] los hijos que quiera" (237). Desde el entramado ideológico anarquista, los ideales de libertad, igualdad, antiestatismo y anticlericalismo suministran la materialidad discursiva, para articular un mecanismo de contrapoder hegemónico, el cual otorgue a las mujeres una alternativa para satisfacer sus deseos sexuales de unión con otro cuerpo sin la necesidad de incurrir en prácticas sexuales matrimoniales, de las que se pueden desprender: el adulterio, las enfermedades venéreas y la prostitución, entre otras. Estos hábitos, resultan altamente nocivos, tanto para las mujeres como para la sociedad en general.

llevándose a sus hijos. Sin embargo, Chazal la persigue constantemente, por este motivo Flora decide viajar a Perú, con el deseo de reclamar su herencia y así obtener algún grado de autonomía económica. Por el contrario, recibe el rechazo de su familia paterna, debiendo regresar a Europa con las manos vacías. Esta experiencia, la llenó de determinación e inicia su activismo político a favor de los derechos obreros y de las mujeres.

5 La maternidad en los textos anarquistas es comprendida como una herramienta de oposición al aparato estatal, ya que las madres deben adoctrinar a sus hijos sobre los peligros que implica el patriotismo. Además, deben enseñarles sobre los beneficios libertarios del anarquismo. 
La solución planteada por la sujeto del enunciado, para no contraer matrimonio ni abstenerse de las pulsiones eróticas femeninas, se encontraría en el ejercicio del amor libre. A causa de la filiación del periódico La Voz de la Mujer con el comunismo anárquico, la propuesta del amor libre, posee una clara orientación individualista antiorganizacionista, ${ }^{6}$ permitiendo a las mujeres expresar sus intereses y deseos, al momento de establecer una relación amatoria. De esta manera, sus uniones no serían vitalicias como en el matrimonio, al contrario, su duración estaría determinada por la presencia o ausencia del amor. En este contexto las mujeres al finalizar la unión con un hombre podrían iniciar una nueva relación amorosa, por supuesto con otro hombre. ${ }^{7}$ Así, la identidad sexual femenina prescrita por los discursos de poder expresa importantes tensiones en las estructuras familiares. Pepita Guerra declara:

Es decir que la unión termine cuando termine el amor, y que si yo porque la gana me da, no quiero estar sujeta á [sic] ningún hombre, no se me desprecie, porque cumpliendo y satisfaciendo la ley natural y un deseo propio, tenga un amante. (237)

Mediante esta revolucionaria estrategia amatoria, las mujeres invertirían la pasividad conferida por el matrimonio, dando paso a sujetas deseosas y autónomas. Por lo tanto, con esta propuesta emancipadora, las mujeres anarquistas comienzan a inventarse a sí mismas, desarticulan los andamiajes identitarios articulados y representados por el sistema patriarcal. Desajustan el imaginario androcéntrico de la sexualidad femenina y se anticipan a la tradición poética de mujeres del siglo XX, quienes ven el cuerpo femenino como una instancia liberadora de la inmovilidad biológica/cultural impuesta por los lenguajes ajenos de la masculinidad.

Sin embargo, Pepita Guerra señala el adverso escenario que enfrenta el amor libre en la sociedad capitalista argentina de fin de siglo, pues solamente alcanzarán las mujeres tal grado de emancipación en el establecimiento de una sociedad fundada en los contenidos ideológicos anarquistas, ya que es la única forma de trocar las estructuras configuradoras de: las relaciones de producción y las sexo-genéricas. La autora define este fenómeno al decir:

6 Este tipo de orientación buscaba la eliminación de las estructuras sociales existentes, con el objetivo de crear un nuevo orden social (justo e igualitario) organizado bajo el principio "de cada uno, según sus fuerzas; a cada uno, según su necesidad", vale decir, no se contemplan organizaciones determinadas por relaciones jerárquicas.

7 No se trata de establecer uniones con múltiples parejas sexuales, ya que sería considerado un comportamiento libertino y, por lo tanto, degenerado. Las anarquistas, promotoras del "amor libre" se declaran monógamas, su discurso pone atención en la libertad de acción. 
Yo no digo que en la presente sociedad pueda una mujer tener el grado de libertad que anhelamos, pero sí, que en nuestra futura y próxima sociedad, donde nada faltará a nadie, donde nadie padecerá hambre ni miseria, allí sí que querremos el amor libre completamente. (237)

Aunque los obstáculos puestos por la sociedad decimonónica argentina impedirían activar el dispositivo del "amor libre", la sujeto problematiza aún más el discurso familiar nacional y, en un gesto de autorepresentación, transgrede las sólidas construcciones culturales que dinamizan los ámbitos de acción asignados a la sujeto femenino. En un movimiento arriesgado, insiste en que si su deseo la anima a "no estar sujeta á [sic] ningún hombre", se buscará un amante y criará "dos, cuatro ó [sic] los hijos que quiera". Accede a su propia subjetividad, a una conciencia de su Yo tanto personal como público, no se concibe exclusivamente como un complemento reproductor del orden masculino, vincula la maternidad a un proceso "opcional" no a una "obligación" predestinada, ni menos como la única alternativa que otorgue valor a su cuerpo. Pepita Guerra señala:

En la sociedad presente no lo hago, porqué [sic] como yo no quiero ser la fregona de ningún hombre y no siendo suficiente mi salario para mantenerme á [sic] mí, menos á [sic] mis hijos, pues yo creo que si los tuviera, me vería obligada por huir de ser la hembra de uno ó [sic] ser la de diez más. (237)

Emerge con fuerza la figura de la mujer soltera, lugar que suscita temor en el imaginario androcéntrico, debido a que constituye un objeto de peligro para las fantasías de representación masculina. Sin embargo, donde las mujeres solteras provocan mayores estragos es en el espacio familiar, porque como señalamos anteriormente, el cuerpo femenino es instrumentalizado como una máquina reproductora, al servicio de los objetivos trazados por el proyecto nacional argentino. Por consiguiente, las mujeres solteras amenazarían la figura arquetípica de la madre-nación, debido a sus tendencias a no procrear. Apelando a su experiencia, Pepita Guerra señala que estima más su independencia sobre la sujeción masculina, puesto que no quiere "ser la fregona de ningun [sic] hombre", incluso denuncia los estragos que han producido, los bajos salarios de la sociedad capitalista, en su potencial maternidad y en el cuerpo de los infantes-no nacidos. Frente a este escenario de injusticias, dolor y violencia, Guerra se resiste a ser colonizada por los hombres, prefiere mantenerse sola (soltera para la narrativa legal), volviéndose una sujeto altamente peligrosa para el mundo masculino, por lo mismo temida por sus integrantes y finalmente incomodando a los centros de poder, quienes la nominan como un "problema social" que debe ser controlado. 
Pese a situar aquí el discurso sobre la sexualidad y el eros femenino como un tema de discusión en la agenda de la prensa femenina argentina, dicha práctica discursiva se encuentra sesgada por el dispositivo de la matriz heterosexual y su binarismo sexual, vale decir, solamente contempla una forma de deseo y placer femenino: el heterosexual. En este sentido, no se indaga en otras zonas de la identidad sexual femenina o de otros placeres, pues todas aquellas expresiones del erotismo que se desmarquen de la "ley natural" son censuradas por las anarquistas, por ejemplo: la homosexualidad y la masturbación, tanto femenina como masculina son consideradas desviaciones de la "ley natural".

La categoría de género en el texto se encuentra naturalizada y transita en el espacio identitario de lo posible. Según la reglamentación dispuesta por la matriz heterosexual, la sujeto se mueve desde el polo femenino al masculino, reduciendo el espectro de posibilidades a una dicotomía de términos, entre los que se cuentan: natural/contra-natura, virtuoso/corrupto, heterosexual/homosexual y normal/ anormal. Es decir, legitima la normativización de la moral sexual emanada de los centros de poder, expresiones como: "Sí, la ley natural nos impele á [sic] amar continuamente" o "porque cumpliendo y satisfaciendo la ley natural", corroboran esta idea.

En sus esfuerzos por legitimar la opción de moral sexual anarquista y desacreditar las prácticas referidas a la moral burguesa, Pepita Guerra acusa a este último grupo de hipócritas, ya que desea desequilibrar, en un ejercicio de contra-poder, la veracidad de las acciones del grupo social dominante. Para la sujeto del texto, la resolución final de las mujeres burguesas, bajo el imperativo del ideal familiar heterocapitalista, implica traicionar los deseos del cuerpo femenino y atentar contra las leyes de la naturaleza. Vale decir, para la voz enunciante del texto, las prácticas de la sexualidad estarían determinadas por el privilegio social. Así lo explica Pepita Guerra al señalar:

Ni tampoco (si llega el caso) ahogar en mis entrañas para conservar la negra honrilla, al fruto de mi amor ó [sic] momentánea unión; quede eso para la distinguida' niña fulanita que va (en tiempo de invierno) á [sic] reponer su apreciable salud á [sic] la estancia de tal ó [sic] cual, y que a los pocos meses ¡o prodigio! vuelve sana y desembarazada ${ }^{8}$ de la pícara enfermedad que la aquejaba (238).

Finalmente, cierra su intervención pública reivindicando beligerantemente las luchas del género, por sobre los pactos ideológicos suscritos con los anarquistas. Imputa a aquellos camaradas, adversarios del "amor libre", de una falsa militancia,

8 El uso de negrita corresponde al texto original. 
porque, al criticar la propuesta del "amor libre", conspirarían en contra de las camaradas mujeres y la causa anarquista misma.

Haciendo uso de un espacio (no resuelto aún) saturado de violencia, asignan a los "falsos anarquistas" el nombre de: "maricas". Es evidente, la ira que siente la sujeto de la enunciación, por ser el blanco de los constantes ataques y enjuiciamientos, por parte de los hombres anarquistas/burgueses. Sin embargo, emplear el locus del homosexual con el objetivo de degradar a los dominadores, evidencia el modelamiento efectuado por el guion performativo de la matriz heterosexual. Su discurso emancipador se entrampa en los dispositivos del poder al feminizar a los "falsos anarquistas", ya que el "marica" al carecer de virilidad constituye la figura de un no-hombre, fenómeno similar acaecido a las mujeres, quienes han sido valoradas por el sistema patriarcal, como el término devaluado al no poseer las propiedades del sujeto masculino, además funcionan como el soporte fundamental para que este último se constituya como un sujeto de poder. De manera inconsciente, con esta operación lingüística, Pepita Guerra margina violentamente al sector de homosexuales, confinando las prácticas sexuales y sus múltiples identidades al ejercicio normativo de ellas.

Al revisar analítica y críticamente el texto de Pepita Guerra, observamos, a través del ejercicio escritural llevado a cabo por ella, la elaboración de estrategias discursivas que contribuyen al agrietamiento de los discursos modernizantes, efectuando operaciones deconstructivas en el sistema de dominación masculina. Además de denunciar la doble explotación (el capital y el patriarcado) experimentada por las mujeres, plantea mecanismos de resistencia frente a los lineamientos discursivos hegemónicos. El aporte más significativo de este artículo reside en la instalación en el debate público del eros y la sexualidad femenina, voz que por mucho tiempo había sido silenciada y dicha por "otros". Sus propuestas se desplazan de forma inestable, en una suerte de juego tentativo, inundando de múltiples significaciones al texto, dotándolo de permeabilidad.

Lo interesante de este texto está en que se opone a los ejercicios normativos del Estado, pero sobre todo desestabiliza el discurso de la estirpe nacional; reflexiona sobre otros modelos familiares, por ejemplo, el de familia monoparental. Además, coloca en tela de juicio las "bondades del matrimonio" y aparece con fuerza la mujer soltera instaurando un espacio de autonomía femenina. Ahora bien, no desmonta de forma plena la imagen de un femenino heterosexual, el cual ha contribuido a la discriminación experimentada por mujeres lesbianas, ya que la matriz heterosexual persiste en disciplinar el deseo femenino en una sola dirección, coaccionando la manifestación de otras prácticas eróticas y sexuales femeninas. 


\section{Obras citadas}

Alberdi, Juan Bautista. Bases y puntos de partida para la organización política de la República de Argentina.

Althusser, Louis. "Ideología y Aparatos Ideológicos de Estado". En Ideología. Un mapa de la cuestión. Žižek, Slajov (ed.). México: Fondo de la Cultura Económica, 2003: 115-155.

Bauman, Zygmunt. "De peregrino a turista, o una breve historia de la identidad". En Cuestiones de identidad cultural. Comp. Stuart Hall y Paul Dugay. Bueno Aires: Amorrurtu, 2003: 40-68

Derrida, Jacques. Ante la ley. Madrid: Avarigani, 2011.

Fernández-Martorell, Mercedes. Capitalismo y cuerpo. Crítica de la razón masculina. Madrid: Ediciones Cátedra, 2018.

Guerra, Lucía. Mujer y escritura: fundamentos teóricos de la crítica feminista. Chile: Editorial Cuarto Propio, 2008.

Guerra, Pepita. [Sin título]. En La mujer y el espacio público. El periodismo femenino en la Argentina del siglo XIX. Compiladora Francine Masiello. Buenos Aires: Feminaria Editora, 1994.

Hall, Stuart. “¿Quién necesita identidad?”. En Cuestiones de identidad cultural. Comp. Stuart Hall y Paul Dugay. Buenos Aires: Amorrurtu, 2003: 13-39.

Masiello, Francine. Entre civilización y barbarie. Mujeres, Nación y Cultura literaria en la Argentina moderna. Buenos Aires: Beatriz Viterbo Editora, 1997.

Padilla, Miguel. "El Anarquismo". Academia Nacional de Ciencias Morales y Politicas.

Ramos, Julio. Desencuentros de la modernidad en América Latina. Literatura y politica en el siglo XIX. Chile: Editorial Cuarto Propio, 2003.

Said, Edward. "Adversarios, públicos, partidarios y comunidad". Reflexiones sobre el exilio. Ensayos literarios y culturales. Debate, 2005: 127- 162.

Spivak, Gayatri. ¿Puede hablar el subalterno? Trad. José Amícola. Buenos Aires: El cuenco de plata, 2011: 5-111. 